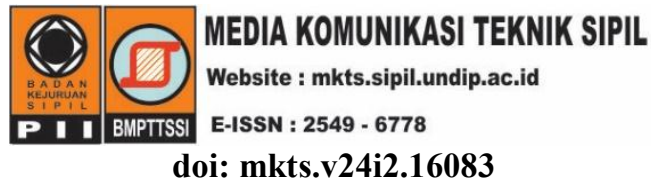

\title{
Dampak Kerusakan Dini Perkerasan Jalan terhadap Kerugian Aspek Finansial
}

\author{
Marsinta Simamora, Diarto Trisnoyuwono, Anastasia Hendrina Muda \\ Jurusan Teknik Sipil, Politeknik Negeri Kupang \\ *) diartopoltek@gmail.com
}

Received: 26 September 2017 Revised: 3 Desember 2018 Accepted: 6 Desember 2018

\begin{abstract}
National road management is not optimal and inefficient, the indications can be seen from the number of early damage cases of the road construction found. Indeed, natural damage to road construction is unavoidable but it becomes a problem if the damage occurs not long after the road product is handed over to the road manager or the government. Then the next question can arise whether the phenomenon of early pavement damage will cause harm to both road users and the government.This study aims to show the thinking framework of financial consequences and apply it through a model due to the occurrence of premature damage. Referring to the concept of benefit value that is represented by road conditions over the life of the service, then roads that have been damaged before their construction ends will result in losses due to loss of benefits. Based on this concept, a simulation was conducted using a national road data. Simulation results show that there is an estimated financial loss due to the occurrence of early damage. For early damage with a condition value of loss of 36 then the estimated loss is Rp 458,257,899.41 per kilometer. Estimated average loss per kilometer for each loss of one unit of condition value is Rp 12,72,386.09. The results of this study also show that roads that do not suffer early damage do not cause losses or losses are zero.
\end{abstract}

Keywords: Financial consequences, premature damage, road pavement

\begin{abstract}
Abstrak
Pengelolaan jalan nasional (JN) belum optimal dan kurang efisien, indikasinya dapat dilihat dari banyaknya kasus - kasus kerusakan dini konstruksi jalan yang ditemukan. Memang secara alami kerusakan konstruksi jalan tidak dapat dihindari tetapi yang menjadi masalah jika kerusakan tersebut terjadi tidak lama setelah produk jalan diserahkan kepada pengelola jalan atau pemerintah. Maka selanjutnya dapat muncul pertanyaan apakah fenomena kerusakan dini perkerasan jalan apakah akan menimbulkan kerugian di pihak pengguna jalan maupun pemerintah. Penelitian ini bertujuan untuk menunjukkan kerangka berfikir konsekuensi dari aspek finansial dan mengaplikasikannya melalui suatu model akibat terjadinya kerusakan dini. Mengacu pada konsep nilai manfaat yang direpresentasikan melalui kondisi jalan selama umur layannya, maka jalan yang mengalami kerusakan sebelum masa layan konstruksinya berakhir akan menimbulkan kerugian karena hilangnya sejumlah manfaat. Berdasarkan konsep ini dilakukan suatu simulasi dengan menggunakan data jalan nasional. Hasil simulasi menunjukkan terdapat perkiraan kerugian finansial akibat terjadinya kerusakan dini. Untuk kerusakan dini dengan nilai kondisi yang hilang sebesar 36 maka perkiraan kerugian adalah Rp 45.257.899,41 tiap kilometer. Perkiraan kerugian rata-rata per kilometer untuk setiap kehilangan satu unit nilai kondisi adalah Rp 12.729.386,09. Hasil penelitian ini juga menunjukkan bahwa jalan yang tidak mengalami kerusakan dini tidak menimbulkan kerugian atau kerugiannya adalah nol.
\end{abstract}

Kata Kunci: Konsekuensi finansial, kerusakan dini, perkerasan jalan

\section{Pendahuluan}

Pengelolaan jalan nasional (JN) belum optimal (TPEKTN, 2009). Berdasarkan data Ditjen Bina
Marga (2010), total panjang jaringan jalan yang ada di Indonesia mencapai $376.176 \mathrm{~km}$ yang terdiri dari jalan tol sepanjang 741,97 $\mathrm{km}(0,20 \%)$, jalan nasional non-tol $38.569 \mathrm{~km}(10,25 \%)$, jalan 
provinsi $48.681 \mathrm{~km}(12,94 \%)$, jalan kabupaten $255.253 \mathrm{~km}(67,85 \%)$, dan jalan kota $32.932 \mathrm{~km}$ $(8,75 \%)$. Data tersebut menunjukkan bahwa kebutuhan jalan di Indonesia didominasi oleh jalan daerah sehingga pelayanan jalan daerah harus memberikan pelayanan yang baik bagi masyarakat pengguna jalan. Sementara kondisi perkerasan jalan daerah di Indonesia sangat memprihatinkan seperti yang dijelaskan Dardak (2010) dalam Pandey (2013), bahwa $61,11 \%$ jalan propinsi berada dalam kondisi tidak mantap, dan 53,01\% jalan kabupaten/kota dalam kondisi tidak mantap. Sebagian besar permasalahan tersebut merupakan suatu kondisi dimana jalan rusak sebelum umur rencananya. Ada beberapa contoh kasus, diantaranya Kirmanto (2012) menyebutkan bahwa jalan pantura Pulau Jawa tidak tahan 2 tahun akibat terjadinya beban muat berlebih (overloading). Di samping itu, Simamora \& Hatmoko (2014) menyebutkan bahwa pengelolaan jalan nasional non toll pada Tahun 2011 dan 2012 sangat tidak efisien dan tidak efektif. Ha ini dapat dilihat dari nilai jump performance pada tahun 2011 adalah 0 $\mathrm{km} / \mathrm{m}$ dan tahun 2012 adalah $0,507 \mathrm{~m} / \mathrm{km}$.

Selain itu kerusakan jalan sebelum umur layannya tercapai bisa diakibatkan dari buruknya proses perencanaan dengan menghasilkan desain lapis perkerasan jalan yang tidak sesuai kondisi atau kebutuhan nyata di lokasi. Proses pelaksanaan konstruksi jalan yang buruk bisa menjadi pelengkap dari serangkaian faktor penyebab kerusakan dini konstruksi jalan.

Pandey (2013) menyampaikan bahwa kerusakan jalan sangat mempengaruhi pengguna jalan dengan meningkatnya biaya pengguna jalan atau road user cost (RUC). Memang kerusakan pada fasilitas tidak dapat dihindari (Hudson et al., 1987; Zhang et al., 2012). Namun yang sering menjadi masalah adalah kerusakan-kerusakan dini perkerasan jalan terkesan tidak perlu untuk dipertanggung jawabkan, sebab pada umumnya kerusakan yang seperti itu selalu ditangani dengan perbaikanperbaikan sepanjang biaya tersedia. Keadaan ini perlu diperbaiki dengan membangun kerangka berfikir konsekuensi secara finansial akibat terjadinya kerusakan dini, dimana kerusakan dini dapat didefinisikan sebagai kerusakan yang terjadi sebelum umur layannya dilalui (Suroso, 2008).

Penelitian ini bertujuan untuk menggambarkan dampak finansial akibat kerusakan dini perkerasan jalan. Konsekuensi finansial kerusakan dini perkerasan jalan adalah kerugian secara moneter yang merupakan fungsi dari kehilangan manfaat, nilai investasi pembangunan $(\mathrm{P})$, pemeliharaan berkala (PB) dan pemeliharaan rutin (PR) perkerasan jalan. Selanjutnya, dilakukan simulasi menggunakan data jalan yang tersedia untuk menemukan sejumlah kerugian akibat kerusakan dini jalan.

\section{Faktor - faktor penyebab kerusakan jalan}

Kerusakan jalan ditunjukkan dengan perubahan bentuk permukaan jalan. Dampak dari ketidak patuhan terhadap regulasi yang ditetapkan oleh pemerintah akan menyebabkan kerusakan struktural jalan daerah. Kerusakan struktural juga disebabkan karena beban kendaraan yang tidak sesuai dengan kelas jalan. Di samping itu penyebab kerusakan awal konstruksi jalan daerah adalah mutu konstruksi tidak sesuai dengan standar, beban gandar kendaraan tidak sesuai dengan kelas jalan dan disfungsi sistem drainase (Pandey, 2013)

\section{Life-cycle cost analysis (LCCA)}

Metode LCCA dapat digunakan untuk mempertimbangkan beberapa pilihan yang berhubungan dengan biaya, misalnya, biaya pembangunan, pemeliharaan, dan pengoperasian selama rentang umur layannya. Xu \& Tsai (2012) dalam penelitiannya pada ruas jalan SPS-5 di California menyimpulkan bahwa terdapat konsekuensi finansial rata-rata sebesar 27,7\% akibat terjadinya keterlambatan pemeliharaan pada jalan dengan tebal perkerasan 1,97 in $(5 \mathrm{~cm})$.

\section{Umur rencana}

Umur rencana perkerasan jalan adalah sejumlah tahun dari saat jalan tersebut dibuka untuk lalu lintas kendaraan sampai diperlukan suatu perbaikan yang bersifat struktural, sampai diperlukan pelapisan ulang suatu perkerasan. Selama umur tersebut pemeliharaan perkerasan jalan tetap dilakukan. Seperti pelapisan nonstruktural yang berfungsi sebagai lapisan aus, umur rencana untuk perkerasan lentur jalan baru umumnya dilakukan 20 tahun, sedangkan untuk peningkatan jalan 10 tahun.Untuk jalan yang lebih dari 20 tahun dinilai tidak lagi ekonomis karena tidak relevan dengan pertumbuhan lalu lintas yang sangat tinggi (Sukirman, 1999).

\section{Kondisi pelayanan perkerasan jalan}

Kondisi pelayanan perkerasan jalan dapat dikategorikan sebagai perkerasan jalan mantap, tidak mantap, dan kritis (Munggarani, 2017).

a. Kondisi pelayanan mantap merupakan kondisi pelayanan sejak konstruksi masih baru sampai dengan kondisi pelayanan pada batas kemantapan (akhir umur rencana) dan penurunan nilai kemantapan wajar seperti yang 
diperhitungkan. Termasuk dalam kondisi ini adalah jalan dengan kondisi baik dan sedang.

b. Kondisi pelayanan tidak mantap adalah kondisi pelayanan berada di antara batas kemantapan sampai dengan batas kritis. Termasuk dalam kondisi ini adalah jalan dengan kondisi rusak atau kurang baik.

c. Kondisi kritis adalah kondisi pelayanan dengan nilai kemantapan mulai dari batas kekritisan sampai dengan tidak terukur lagi, dimana kondisi tersebut menyebabkan kapasitas jalan menurun. Termasuk dalam kondisi ini adalah jalan dengan kondisi rusak berat atau buruk.

\section{Sisa umur (remaining life) dan nilai sisa (salvage value)}

Sisa umur adalah umur rencana $\left(\mathrm{UR}_{0}\right)$ dikurangi dengan umur saat dilakukan analisis jalan $\left(\mathrm{UR}_{\mathrm{i}}\right)$. Menurut Xu \& Tsai (2012), sisa umur dapat ditentukan dengan menggunakan Persamaan 1.

Sisa umur $=\mathrm{UR}_{0}-\mathrm{UR}_{\mathrm{i}}$

Sementara itu, Xu \& Tsai (2012) menentukan nilai sisa mengacu pada perhitungan yang direkomendasikan oleh Federal Highway Administration (FHWA) [FHWA, 2002] sebagai Persamaan 2.

salvage value $=$

total dollars $\mathrm{x} \frac{\text { remaining life }}{\text { rehabilitation cyclelife }}$

Pada Gambar 1 dapat dilihat bahwa sejak rehabilitasi-1 dilakukan pemeliharaan 1 dan 2 , kemudian rehabilitasi (tipe 1, 2, atau 3).

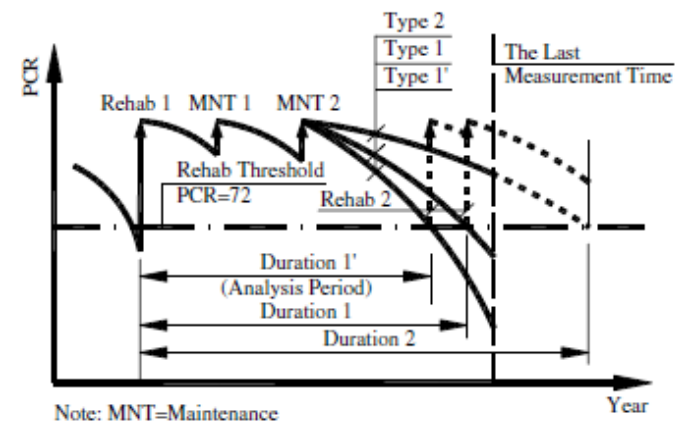

\section{Gambar 1. Kurva penurunan PCR dan periode analisis (Xu \& Tsai, 2012)}

Munggarani (2017) menyampaikan bahwa dalam mempertahankan kinerja perkerasan jalan agar mampu memberikan pelayanan hingga akhir umur yang telah direncanakan sebelumnya, maka diperlukan beberapa tindakan perbaikan kerusakan berupa pemeliharaan jalan. Pemeliharaan jalan adalah penanganan jalan yang meliputi perawatan, rehabilitasi, penunjangan, dan peningkatan.

\section{Manfaat suatu investasi infrastruktur jalan}

Fasilitas jalan dibangun dengan harapan akan memberikan manfaat, baik secara moneter/uang (monetized) maupun non moneter (nonmonetized) (Khurshid et al., 2011; 2009) seperti keamanan dan kenyamanan atau layanan (service). Pelayanan dapat diukur dari nilai kondisi (NK), sementara manfaat secara moneter dapat ditentukan dari jumlah uang atau keuntungan yang diperoleh akibat dari suatu pembangunan jalan, misalnya manfaat sosial dan peningkatan akses transportasi yang mengakibatkan penurunan harga barang disuatu tempat.

Umumnya, fasilitas jalan yang dibangun harus dipelihara (rutin, berkala, rehabilitasi) agar umur layan yang direncanakan dapat tercapai dengan tingkat layanan paling sedikit sebesar layanan minimum penerimaan (minimum acceptable level/MAL) sebagaimana dapat dilihat pada Gambar 2. Pemeliharaan harus dilakukan agar umur rencana (UR) dapat tercapai.

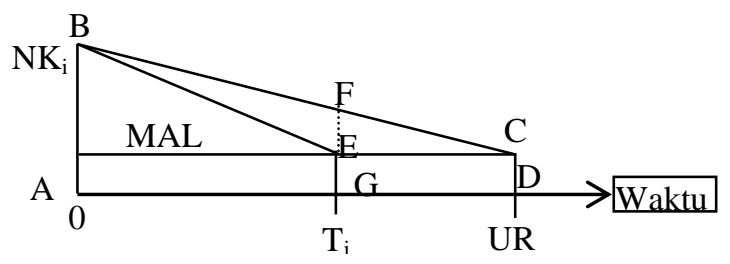

Gambar 2. Ilustrasi nilai kondisi vs waktu

Hal ini dikarenakan sifat dari material yang mengalami pembusukan atau penurunan kondisi (deterioration) (Hudson et al., 1987).

\section{Kehilangan manfaat pada kerusakan dini}

Pada Gambar 2 dapat dijelaskan bahwa daerah ABCD adalah manfaat jenis layanan yang didapatkan dari hasil investasi pembangunan dan pemelilahraan. Apabila terjadi kerusakan dini atau rusak sebelum waktunya akan mengakibatkan kehilangan manfaat. Suatu kondisi yang mengalami kerusakan dini, yaitu kondisi pada umur layan (waktu layan) Ti. Pada kondisi tersebut NK adalah sebesar MAL, seharusnya adalah sebesar F. Atau dapat disebut juga bahwa kondisi pada saat waktu $T_{i}$ yaitu sebesar MAL seharusnya terjadi pada akhir UR, yang mana keadaan ini dapat menjelaskan telah terjadinya kehilangan waktu layan jalan. Kehilangan manfaat (KM) pada peristiwa $T_{i}$ dimana saat itu NK adalah MAL, adalah sebesar luasan BCE. Dengan demikian KM dapat dihitung menggunakan Persamaan 3. 
$\mathrm{KM}=\mathrm{ABCD}-\mathrm{ABECD}$

dimana KM merupakan manfaat yang hilang pada saat $\mathrm{Ti}, \mathrm{ABCDmerupakan}$ manfaat total, dan ABECD merupakan manfaat yang terjadi saat $\mathrm{Ti}$

$\mathrm{ABCD}=\frac{\mathrm{MAL}+100}{2} \times \mathrm{UR}$

$\mathrm{ABECD}=\frac{100+\mathrm{NKi}}{2} \times \mathrm{Ti}+\frac{\mathrm{NKi}+\mathrm{MAL}}{2} \times(\mathrm{UR}-\mathrm{Ti})$

\section{Nilai saat ini $\left(\mathbf{P}_{\mathbf{W}}\right)$}

Konsep biaya pengelolaan dan manfaat dapat dilihat pada Gambar 3. Biaya membangun dinyatakan dalam $\mathrm{I}_{0}$, biaya pemeliharaan rutin $\mathrm{PR}$, pemeliharaan berkala $\mathrm{PB}$, dan manfaat uang yang akan didapatkan $\mathrm{M}$.

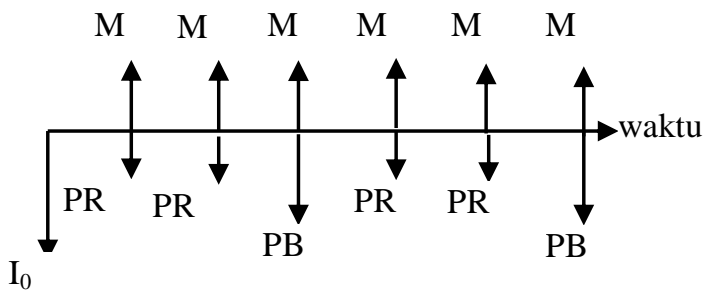

\section{Gambar 3. llustrasi arus kas biaya pengelolaan dan manfaat pada jalan}

PW (present worth) adalah nilai pada saat ini. Pengeluaran dan manfaat/penghematan (saving) dihitung menjadi harga saat ini. Dalam penentuan nilai PW, tingkat suku bunga (i) dan waktu (n) menjadi faktor-faktor yang turut berperan, dan dapat dihitung menggunakan Persamaan 4 :

$\mathrm{PW}=\mathrm{I} 0+\sum_{\mathrm{p}=1}^{\mathrm{p}=\mathrm{n}}(\mathrm{F}) \mathrm{i}$

dimana $\mathrm{P}_{\mathrm{W}}$ adalah nilai saat ini $(\mathrm{Rp}), \mathrm{I}_{0}$ adalah biaya membangun awal (Rp), $\mathrm{F}$ adalah arus kas (flow of money) pengeluaran dan penghematan/ manfaat yang diperoleh (Rp), I adalah tingkat suku bunga (interest rate), dan $\mathrm{p}$ adalah periode waktu (tahun), $\mathrm{p}=1,2,3 \ldots . . \mathrm{n}$

\section{Nilai kehilangan manfaat}

Nilai kehilangan manfaat akan dinilai secara moneter menggunakan Persamaan 5.

$\mathrm{K}=\mathrm{KM} \times \mathrm{C}$

dimana $\mathrm{K}$ adalah nilai kehilangan manfaat, KM adalah kehilangan manfaat (luas nilai kondisi (manfaat) yang hilang), $\mathrm{C}$ adalah koefisien harga/nilai tiap unit nilai kondisi (NK)

Jika biaya investasi, pemeliharaan, dan manfaat uang lainnya adalah $\mathrm{PW}$, maka tiap unit manfaat layanan memiliki biaya sebesar PW dibagi luas daerah $\mathrm{ABCD},(\mathrm{A})$. Jika biaya tiap unit manfaat disebut dengan koefisien nilai manfaat $\mathrm{C}$, maka $\mathrm{C}$ dapat ditentukan menggunakan Persamaan 6.

$C \frac{P_{W}}{A_{M}}$

dimana $\mathrm{C}$ merupakan koefisien harga tiap unit manfaat (Rp/unit), $\mathrm{P}_{\mathrm{W}}$ adalah total biaya saat ini (arus kas: membangun, memelihara, dan manfaat sosial lainnya) dan $A_{M}$ adalah manfaat rencana, yaitu luas daerah ABCD (manfaat layanan)

\section{Metode Penelitian}

Penelitian ini dikategorikan penelitian studi kasus yang akan dilakukan dengan beberapa tahap, yaitu: (1) menentukan lokasi studi, (2) pengambilan data sekunder, (3) pengambilan data PCI, (4) penentuan cash flow (CF) pengelolaan jalan, (5) penentuan present value (PV) dari $\mathrm{CF}$.

Penelitian dilaksanakan selama tiga bulan, yaitu bulan September sampai dengan Desember 2016 di Kota Madya Kupang (Jalan Lopo Indah) dan batas Kota Kupang dengan Kabupaten Kupang (jalan lingkar luar, di belakang Kampus UndanaKupang).

Data sekunder, yaitu riwayat penanganan jalan, waktu penanganan, biaya penanganan, jenis konstruksi saat penanganan, dan manfaat yang diperoleh, nilai kondisi jalan saat pemeriksaan dan yang direncanakan. Pada studi kasus nilai manfaat (M) adalah merupakan suatu asumsi/perkiraan.

\section{Hasil dan Pembahasan}

Berdasarkan data dari Kementerian PU tahun 2012 diperoleh harga pemeliharaan jalan nasional sebagaimana yang disajikan pada Tabel 1. Untuk menentukan nilai PR dan PB saat ini diperlukan informasi indeks harga. Berdasarkan data harga tahun 2011 dan 2012, maka nilai pertumbuhan atau indeks harga rata-rata $\left(\mathrm{i}_{\text {avr }}\right)$ dapat ditentukan dengan Persamaan 7:

$\operatorname{iavr}=\frac{\sum_{\mathrm{k}=1}^{\mathrm{l}} \mathrm{ik}}{\mathrm{l}}$

dimana $i_{\text {avr }}$ merupakan pertumbuhan rata-rata atau indeks harga rata-rata (\%), ik merupakan pertumbuhan atau indeks harga $(\%)$ pemeliharaan pada masing-masing type pemeliharaan dan type jalan, yaitu (harga 2012-harga 2011) dibagi (harga 2011) dikali 100\%, $\mathrm{k}$ merupakan jenis-jenis pemeliharaan sesuai dengan type jalan; $k=1,2, \ldots 1$ Berdasarkan data harga tahun 2011 dan 2012 yang diperoleh, indeks harga rata-rata diperoleh sebesar $3.10 \%$ sebagaimana dapat dilihat pada Tabel 2 . 
iavr $=\frac{\sum_{\mathrm{k}=1}^{\mathrm{n}} \mathrm{ik}}{\mathrm{n}}=\frac{31,01}{10}=3,10 \%$

Nilai pemeliharaan rutin pada tahun 2017 untuk jalan nasional adalah:

Untuk lebar jalan 5 meter:

$\mathrm{n}=5, \mathrm{i}=3,10 \%$

$\mathrm{PR}_{2012}=\mathrm{Rp} 41.000 .000$

$\mathrm{PR}_{2017}=41.000 .000(1+0.031)^{5}$

$=\operatorname{Rp} 47.761414,81$

Untuk lebar jalan 6 meter:

Nilai pada tahun 2016; $\mathrm{n}=4, \mathrm{i}=3,10 \%$,

$\mathrm{PR}_{2012}=\operatorname{Rp} 62.000 .000=$

$\mathrm{PR}_{2016}=62.000 .000(1+0,031)^{4}$

$=\operatorname{Rp} 70.052 .937,43$

Nilai pada Tahun 2017: $\mathrm{n}=5, \mathrm{i}=3,10 \%$,

$\mathrm{PR}_{2012}=\mathrm{Rp} 62.000 .000$,

$\mathrm{PR}_{2017}=62.000 .000(1+0,031)^{5}$

$=\operatorname{Rp} 72.224 .578,49$
Pada penelitian ini, lebar jalan dianggap 6 meter. Dengan demikian, untuk panjang jalan $5 \mathrm{~km}$, PR tahun 2016 adalah lima kali Rp 70.052.937,43 yaitu Rp350.264.687, sedangkan untuk tahun 2017 PR adalah lima kali Rp 72.224,578,49 yaitu Rp 361.122.892.

\section{Nilai kondisi dan biaya pengelolaan jalan}

Data yang digunakan adalah data kondisi permukaan jalan PCI. Umur rencana jalan, umur inspeksi adalah merupakan asumsi karena tidak diperoleh data tersebut dari instansi terkait dalam hal ini Balai Jalan Nasional NTT sebagaimana dapat dilihat pada Tabel 3. Sedangkan biaya pemeliharaann rutin menggunakan data standar tahun 2012 Departemen Pekerjaan Umum sebagaimana pada Tabel 4. Io merupakan biaya membangun, $\mathrm{PR}_{1}$ merupakan pemeliharaan rutin tahun-1 (2016), $\mathrm{PR}_{2}$ merupakan pemeliharaan rutin tahun-2 (2017), $\mathbf{M}_{1}$ merupakan manfaat tahun-1, $\mathrm{M}_{2}$ merupakan manfaat tahun-2

Tabel 1. Standar biaya per kilometer

\begin{tabular}{clrr}
\hline \multirow{2}{*}{ No } & \multicolumn{1}{c}{ Uraian } & \multicolumn{1}{c}{$\mathbf{2 0 1 1}$} & \multicolumn{1}{c}{$\mathbf{2 0 1 2}$} \\
\cline { 3 - 4 } I & Pemeliharaan Rutin Jalan Kolektor & Harga satuan (Rp) & Harga satuan (Rp) \\
\cline { 2 - 3 } & Lbr perkerasan s/d 4,5 m dan bahu 2x1 m & & \\
& Lbr perkerasan s/d 5 m dan bahu 2x1 m & 37.075 .085 & 38.000 .000 \\
& Lbr perkerasan s/d 6 m dan bahu 2x1,5 m & 39.598 .208 & 41.000 .000 \\
& Lbr perkerasan s/d 7 m dan bahu 2x2 m & 60.355 .815 & 62.000 .000 \\
& Lbr perkerasan s/d 14 m; bahu 2x2 m & 92.310 .735 & 95.000 .000 \\
II & Pemeliharaan Berkala & 142.035 .214 & 147.000 .000 \\
& Lbr perkerasan s/d 4,5 m dan bahu 2x1 m & & \\
& Lbr perkerasan s/d 5 m dan bahu 2x1 m & 1.010 .726 .164 & 1.043 .000 .000 \\
& Lbr perkerasan s/d 6 m dan bahu 2x1,5 m & 1.102 .200 .412 & 1.137 .000 .000 \\
& Lbr perkerasan s/d 7 m dan bahu 2x2 m & 1.306 .335 .418 & 1.348 .000 .000 \\
& Lbr perkerasan s/d 14 m; bahu 2x2 m & 1.510 .470 .425 & 1.558 .000 .000 \\
\hline
\end{tabular}

Sumber: Ditjen Bina Marga Kementerian PU (2012)

Tabel 2. Penentuan indeks harga rata-rata ( $\left.\mathrm{i}_{\text {avr }}\right)$

\begin{tabular}{clrrr}
\hline \multirow{2}{*}{ No } & \multicolumn{1}{c}{ Uraian } & \multicolumn{1}{c}{$\mathbf{2 0 1 1}$} & $\mathbf{2 0 1 2}$ & Indeks \\
\cline { 3 - 5 } & & Harga satuan (Rp) & Harga satuan (Rp) & Harga (\%) \\
\hline I & Pemeliharaan Rutin Jalan Kolektor & & & \\
1 & Lbr perkerasan s/d 4,5 m dan bahu 2x1 m & 37.075 .085 & 38.000 .000 & 2,49 \\
2 & Lbr perkerasan s/d 5 m dan bahu 2x1 m & 39.598 .208 & 41.000 .000 & 3,54 \\
3 & Lbr perkerasan s/d 6 m dan bahu 2x1,5 m & 60.355 .815 & 62.000 .000 & 2,72 \\
4 & Lbr perkerasan s/d 7 m dan bahu 2x2 m & 92.310 .735 & 95.000 .000 & 2,91 \\
5 & Lbr perkerasan s/d 14 m; bahu 2x2 m & 142.035 .214 & 147.000 .000 & 3,50 \\
II & Pemeliharaan Berkala & & & 3,19 \\
1 & Lbr perkerasan s/d 4,5 m dan bahu 2x1 m & 1.010 .726 .164 & 1.043 .000 .000 & 3,16 \\
2 & Lbr perkerasan s/d 5 m dan bahu 2x1 m & 1.102 .200 .412 & 1.137 .000 .000 & 3,19 \\
3 & Lbr perkerasan s/d 6 m dan bahu 2x1,5 m & 1.306 .335 .418 & 1.348 .000 .000 & 3,15 \\
4 & Lbr perkerasan s/d 7 m dan bahu 2x2 m & 1.510 .470 .425 & 1.558 .000 .000 & 3,16 \\
5 & Lbr perkerasan s/d 14 m; bahu 2x2 m & 2.859 .711 .484 & 2.950 .000 .000 & 31,01 \\
\hline Jumlah & & & 3,10 \\
\hline indeks harga rata-rata (i
\end{tabular}


Tabel 3. Simulasi data kondisi jalan 7 ruas jalan

\begin{tabular}{cccccc}
\hline No & NK maks & MAL & NKi & Ti & UR \\
\hline 1 & 100 & 40 & 40 & 2 & 5 \\
2 & 100 & 40 & 45 & 2 & 5 \\
3 & 100 & 40 & 50 & 2 & 5 \\
4 & 100 & 40 & 55 & 2 & 5 \\
5 & 100 & 40 & 60 & 2 & 5 \\
6 & 100 & 40 & 65 & 2 & 5 \\
7 & 100 & 40 & 76 & 2 & 5 \\
\hline
\end{tabular}

Keterangan:

$\mathrm{NKi}=$ Nilai kondisi saat inspeksi/pengukuran $(\mathrm{PCI})$

$\mathrm{MAL}=$ minimum acceptable level

$\mathrm{Ti} \quad=$ umur jalan saat inspeksi

UR =umur rencana

\section{Kehilangan manfaat (KM)}

Berdasarkan data kondisi jalan dapat ditentukan kehilangan manfaat (KM) menggunakan Persamaan 3, di mana hasilnya dapat dilihat pada Tabel 5. Hasil perhitungan menunjukkan bahwa semakin buruk nilai kondisi jalan saat pengukuran maka semakin besar kehilangan manfaat yang terjadi.

\section{Nilai saat ini $\left(\mathbf{P}_{\mathrm{W}}\right)$}

Berdasarkan data arus kas pada Tabel 4, ditentukan nilai $\mathrm{P}_{\mathrm{W}}$ menggunakan Persamaan 4 dan hasilnya adalah:

Panjang jalan: $5 \mathrm{~km}$

Biaya membangun

Biaya pemeliharaan-1

2.000.000.000,00 per km 70.052.937,43 per $\mathrm{km}$

Biaya pemeliharaan-2 $72.224 .578,49$ per $\mathrm{km}$

Suku bunga (i) : $12,00 \%$

$\begin{array}{lllr}\mathrm{I}_{0} & = & \mathrm{Rp} & 10.000 .000 .000,00 \\ \mathrm{PR}_{1} & = & \mathrm{Rp} & 350.264 .687,15 \\ \mathrm{PR}_{2} & = & \mathrm{Rp} & 361.122 .892,45 \\ \mathrm{M} 1 & = & \mathrm{Rp} & 1.000 .000 .000,00 \\ \mathrm{M} 2 & = & \mathrm{Rp} & 1.000 .000 .000,00 \\ \mathrm{CF} 1 & = & & (649.735 .312,85) \\ \mathrm{CF} 2 & & & (638.877 .107,55) \\ \mathrm{P} 1=\mathrm{A} 1 /(1+\mathrm{i})^{1} & = & & (580.120 .815,04) \\ \mathrm{P} 2=\mathrm{A} 2 /(1+\mathrm{i})^{2} & = & & (509.308 .918,65) \\ \mathrm{P}_{\mathrm{W}}=\mathrm{I}_{0}+\mathrm{P} 1+\mathrm{P} 2 & =\mathrm{Rp} & 8.910 .570 .266,31\end{array}$

\section{Nilai koefisien harga per unit manfaat layanan (C) dan nilai $\mathrm{K}$}

Setelah diperoleh nilai PW dan besarnya manfaat layanan (AM), maka diperoleh nilai $\mathrm{C}$ menggunakan Persamaan 6. Karena karakteristik masing-masingruas jalan sama, maka diperoleh:

$\mathrm{C}=\frac{\mathrm{PW}}{\mathrm{AM}}=\frac{8.910 .570 .266,31}{350}=\mathrm{Rp} 25.458 .772,19$
Hasil perhitungan menunjukkan bahwa setiap unit nilai kondisi jalan (manfaat layanan) memiliki harga Rp 25.458.772,19. Sehingga apabila terjadi kehilangan sejumlah unit layanan (NK), maka dapat ditentukan akibat finansialnya sebagaimana dapat dilihat pada Tabel 6 yang memperlihatkan makin buruk kondisi jalan makin besar juga nilai manfaat yang hilang. Makin besar unit manfaat yang hilang (KM) maka makin besar juga nilai kerugian yang timbul. Pada Ruas jalan No. 1 dapat dilihat bahwa NK adalah 40 pada saat inspeksi tahun ke-2 $\quad(\mathrm{Ti}=2)$. Dengan $\mathrm{NK}=40$ akan mengakibatkan terjadinya kehilangan NK sebesar 36 dari NK rencana (76-40) dan mengakibatkan kehilangan manfaat layanan (KM) sebesar 90. Kehilangan manfaat KM 90 unit sama dengan kerugian finansial sebesar Rp 2.291.289.497,05.

Demikian juga pada Ruas-7, saat inspeksi $\left(\mathrm{Ti}_{0}=2\right.$ tahun, didapatkan $\mathrm{NK}=76$. Pada saat itu, ternyata NK yang terjadi sesuai dengan rencana $(\Delta \mathrm{NK}=0)$, sehingga tidak ada layanan yang hilang atau $\mathrm{KM}=0$. Dengan demikian tidak ada terjadi kerugian. Keadaan tersebut menunjukkan bahwa kehilangan nilai kondisi (NK) berbanding lurus dengan kehilangan manfaat (KM), dan berbanding lurus juga dengan kerugian $(\mathrm{K})$ sebagaimana dapat dilihat pada Gambar 4. Sehingga, hasil ini menunjukkan bahwa terdapat kerugian finansial apabila terjadi kerusakan dini. Dari data kerugian pada Tabel 6 dapat ditentukan kerugian finansial per kilometer jalan sebagaimana pada Tabel 7 .

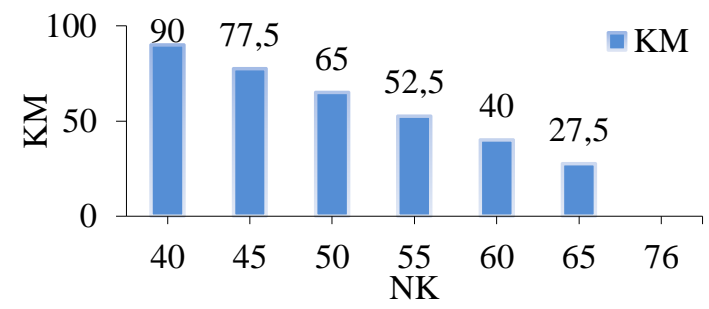

\section{Gambar 4. Nilai kondisi (NK) vs kehilangan manfaat (KM)}

\section{Kerugian tiap kehilangan NK pada kerusakan dini}

Kerugian untuk setiap penurunan kondisi dini per kilometer dengan lebar 6 meter dan manfaat $M$ sama tiap tahun yaitu dua milyard rupiah adalah Rp 12.729.386,09 sebagaimana dapat dilihat pada Tabel 8. Hasil ini juga mengkonfirmasi bahwa ketika tidak terjadi kerusakan dini, kehilangan yang dianggap merugikan tidak ada. Artinya, jika kerusakan yang terjadi akibat penuaan (Hudson et al., 1987) tidak dianggap merugikan pada konsep kerusakaan dini. 
Tabel 4. Daftar biaya membangun, memelihara, dan manfaat

\begin{tabular}{ccccccc}
\hline No & $\begin{array}{c}\text { Panjang } \\
\text { Jalan }(\mathbf{K m})\end{array}$ & $\mathbf{I o} / \mathbf{K m}(\mathbf{R p})$ & $\mathbf{P R}_{\mathbf{1}}(\mathbf{R p})$ & $\mathbf{P R}_{\mathbf{2}}(\mathbf{R p})$ & $\mathbf{M}_{\mathbf{1}}(\mathbf{R p})$ & $\mathbf{M}_{\mathbf{2}}(\mathbf{R p})$ \\
\hline 1 & 5 & 2.000 .000 .000 & 350.264 .687 & 361.122 .892 & 1.000 .000 .000 & 1.000 .000 .000 \\
2 & 5 & 2.000 .000 .000 & 350.264 .687 & 361.122 .892 & 1.000 .000 .000 & 1.000 .000 .000 \\
3 & 5 & 2.000 .000 .000 & 350.264 .687 & 361.122 .892 & 1.000 .000 .000 & 1.000 .000 .000 \\
4 & 5 & 2.000 .000 .000 & 350.264 .687 & 361.122 .892 & 1.000 .000 .000 & 1.000 .000 .000 \\
5 & 5 & 2.000 .000 .000 & 350.264 .687 & 361.122 .892 & 1.000 .000 .000 & 1.000 .000 .000 \\
6 & 5 & 2.000 .000 .000 & 350.264 .687 & 361.122 .892 & 1.000 .000 .000 & 1.000 .000 .000 \\
7 & 5 & 2.000 .000 .000 & 350.264 .687 & 361.122 .892 & 1.000 .000 .000 & 1.000 .000 .000 \\
\hline
\end{tabular}

Tabel 5. Kehilangan manfaat saat inspeksi/pengukuran

\begin{tabular}{cccccccc}
\hline No & UR & Ti & NK maks & NKmin & MAL & NK & KM \\
\hline 1 & 5 & 2 & 100 & 0 & 40 & 40 & 90 \\
2 & 5 & 2 & 100 & 0 & 40 & 45 & 77,5 \\
3 & 5 & 2 & 100 & 0 & 40 & 50 & 65 \\
4 & 5 & 2 & 100 & 0 & 40 & 55 & 52,5 \\
5 & 5 & 2 & 100 & 0 & 40 & 60 & 40 \\
6 & 5 & 2 & 100 & 0 & 40 & 65 & 27,5 \\
7 & 5 & 2 & 100 & 0 & 40 & 76 & 0 \\
\hline
\end{tabular}

Tabel 6. Nilai kerugian akibat kerusakan dini

\begin{tabular}{|c|c|c|c|c|c|c|c|c|}
\hline \multirow{2}{*}{ No } & \multirow{2}{*}{$\mathbf{N K i}$} & \multirow{2}{*}{$\begin{array}{c}\text { NK } \\
\text { rencana }\end{array}$} & \multirow{2}{*}{$\Delta \mathrm{NK}$} & $\mathbf{K M}$ & $\mathbf{T i}$ & UR & $\mathbf{C}$ & $\mathbf{K}$ \\
\hline & & & & unit & Thn & Thn & (Rp/unit) & (Rp) \\
\hline 1 & 40 & 76 & 36 & 90 & 2 & 5 & $25.458 .772,19$ & $2.291 .289 .497,05$ \\
\hline 2 & 45 & 76 & 31 & 77,5 & 2 & 5 & $25.458 .772,19$ & $1.973 .054 .844,68$ \\
\hline 3 & 50 & 76 & 26 & 65 & 2 & 5 & $25.458 .772,19$ & $1.654 .820 .192,31$ \\
\hline 4 & 55 & 76 & 21 & 52,5 & 2 & 5 & $25.458 .772,19$ & $1.336 .585 .539,95$ \\
\hline 5 & 60 & 76 & 16 & 40 & 2 & 5 & $25.458 .772,19$ & $1.018 .350 .887,58$ \\
\hline 6 & 65 & 76 & 11 & 27,5 & 2 & 5 & $25.458 .772,19$ & $700.116 .235,21$ \\
\hline 7 & 76 & 76 & 0 & 0 & 2 & 5 & $25.458 .772,19$ & - \\
\hline
\end{tabular}

Tabel 7. Nilai kerugian per $\mathrm{Km}$ dengan lebar jalan $6 \mathrm{~m}$

\begin{tabular}{|c|c|c|c|c|c|c|c|c|c|}
\hline \multirow{2}{*}{ No } & \multirow{2}{*}{ NKi } & \multirow{2}{*}{$\begin{array}{c}\text { NK } \\
\text { rencana }\end{array}$} & \multirow{2}{*}{$\Delta \mathbf{N K}$} & \multirow{2}{*}{$\begin{array}{l}\text { KM } \\
\text { unit }\end{array}$} & \multirow{2}{*}{$\frac{\text { Ti }}{\text { Thn }}$} & \multirow{2}{*}{$\begin{array}{l}\text { UR } \\
\text { Thn }\end{array}$} & \multirow{2}{*}{$\frac{C}{(\text { Rp/unit })}$} & \multirow{2}{*}{$\frac{K}{(\mathbf{R p})}$} & \multirow{2}{*}{$\begin{array}{c}\text { K/km } \\
(\mathbf{R p})\end{array}$} \\
\hline & & & & & & & & & \\
\hline 1 & 40 & 76 & 36 & 90 & 2 & 5 & $25.458 .772,19$ & $2.291 .289 .497,05$ & $458.257 .899,41$ \\
\hline 2 & 45 & 76 & 31 & 77,5 & 2 & 5 & $25.458 .772,19$ & $1.973 .054 .844,68$ & $394.610 .968,94$ \\
\hline 3 & 50 & 76 & 26 & 65 & 2 & 5 & $25.458 .772,19$ & $1.654 .820 .192,31$ & $330.964 .038,46$ \\
\hline 4 & 55 & 76 & 21 & 52,5 & 2 & 5 & $25.458 .772,19$ & $1.336 .585 .539,95$ & $267.317 .107,99$ \\
\hline 5 & 60 & 76 & 16 & 40 & 2 & 5 & $25.458 .772,19$ & $1.018 .350 .887,58$ & $203.670 .177,52$ \\
\hline 6 & 65 & 76 & 11 & 27,5 & 2 & 5 & $25.458 .772,19$ & $700.116 .235,21$ & $140.023 .247,04$ \\
\hline 7 & 76 & 76 & 0 & 0 & 2 & 5 & $25.458 .772,19$ & - & 0 \\
\hline
\end{tabular}

Tabel 8. Kerugian per Km per kehilangan satu unit NK untuk lebar jalan 6 m

\begin{tabular}{cccccc}
\hline No & NKi & NK rencana & $\Delta \mathbf{N K}$ & $\mathbf{K} / \mathbf{k m}(\mathbf{R p})$ & $\mathbf{K} / \mathbf{k m} / \mathbf{\Delta N K}(\mathbf{R P})$ \\
\hline 1 & 2 & 3 & $4=(3-2)$ & 5 & $6=(5: 4)$ \\
1 & 40 & 76 & 36 & $458.257 .899,41$ & $12.729 .386,09$ \\
2 & 45 & 76 & 31 & $394.610 .968,94$ & $12.729 .386,09$ \\
3 & 50 & 76 & 26 & $330.964 .038,46$ & $12.729 .386,09$ \\
4 & 55 & 76 & 21 & $267.317 .107,99$ & $12.729 .386,09$ \\
5 & 60 & 76 & 16 & $203.670 .177,52$ & $12.729 .386,09$ \\
6 & 65 & 76 & 11 & $140.023 .247,04$ & $12.729 .386,09$ \\
7 & 76 & 76 & 0 & 0 & 0 \\
\hline
\end{tabular}

\section{Kesimpulan}

Sebagaimana tujuan dari penelitian ini yaitu untuk menentukan konsekuensi finansial pada kerusakan dini jalan, dapat disimpulkan bahwa konsep yang dibangun dapat membuktikan bahwa kerusakan dini jalan menimbulkan kerugian secara financial. Jalan dengan lebar 6 meter dan panjang $5 \mathrm{~km}$, 
biaya membangun Rp 2000.000.000 per km, biaya pemeliharaan tahun-1 $\mathrm{Rp} 70.052 .937,43$ per $\mathrm{km}$, biaya pemeliharaan rutin-2 Rp 72.224.578,49 per km, manfaat tahun-1 dan masing-masing $\mathrm{Rp} 1.000 .000 .000,00$ maka untuk satu unit kehilangan manfaat diperoleh kerugian finansial sebesar Rp 25.458.772,19 per kilometer. Kerugian per kilometer untuk setiap kehilangan satu unit NK adalah Rp 12.729.386,09.

\section{Saran}

Hasil penelitian ini menunjukkan bahwa kerusakan dini mengakibatkan kerugian secara finansial oleh karena itu perlu dilakukan evaluasi terhadap seluruh jalan yang mengalami kerusakan dini. Fakta menunjukkan bahwa sangat sulit menemukan riwayat penanganan jalan yang berakibat pada sulitnya melakukan evaluasi kerugian finansial pada kerusakan dini jalan, oleh karena itu, selanjutnya perlu dilakukan suatu penelitian untuk membentuk bank data riwayat penanganan jalan, baik jalan nasional, propinsi, dan kabupaten, seperti biaya pembangunan awal, pemeliharaan rutin, pemeliharaan berkala, manfaat yang diperoleh, dan umur rencana jalan.

\section{Ucapan Terima Kasih}

Penelitian ini dibiayai oleh Politeknik Negeri Kupang pada Tahun 2016. Oleh karena itu, ucapan terima kasih banyak disampaikan kepada Kementerian Ristekdikti dan Politeknik Negeri Kupang.

\section{Daftar Pustaka}

Ditjen Bina Marga D. P. U., (2010). Rencana Strategis 2010-2014.

Ditjen Bina Marga D. P. U., (2012). Standar biaya penanganan jalan tahun 2011 dan 2012. Jakarta: Sub. Direktorat Informasi dan Komunikasi, Dir. Bina Program, Ditjen. Bina Marga, Kementerian Pekerjaan Umum.

Hudson, R., Hass, R., and Uddin, W., (1987). Infrastruktur management: Integrating design, construction, maintenance, rehabilitation and renovation, New York: .Mc Graw-Hill.

Kirmanto, D. (2012). Overload percepat kerusakan jalan Pantura
Khurshid, M. B., Irfan, M., and Labi, S., (2009). Comparing the Methods for Evaluating Pavement Intervention - Evaluation and Case Study. Transportation res. rec., 2108, 25-36.

Khurshid, M. B., Irfan, M., \& Labi, S. (2010). Optimal Performance Threshold Determination for Highway Asset Interventions: Analytical Framework and Application. Journal of Transportation Engineering, 137(2), 128-139.

Munggarani, A. N., \& Wibowo, A. (2017). Kajian Faktor-Faktor Penyebab Kerusakan Dini Perkerasan Jalan Lentur dan Pengaruhnya terhadap Biaya Penanganan. Journal Infrastruktur PUPR.

Pandey, S. V. (2013). Kerusakan Jalan Daerah Akibat Beban Overloading. TEKNO, 11(58).

Simamora, M., \& Hatmoko, J. U. D. (2014). Efficiency and Effectivness of The Non-Toll National Roads Management Based on The Performance Jump of Pavement Condition. Jurnal Dinamika Teknik Sipil, 10(1).

Sukirman, S. (1999). Perkerasan lentur jalan raya. Bandung: Penerbit Nova.

Suroso, T. W., (2008). Faktor-faktor penyebab kerusakan dini pada perkerasan jalan. Bandung: Puslitbang Jalan dan Jembatan, Departemen Pekerjaan Umum, R. I.

TPEKTN (Tim Pemantauan dan Evaluasi Kinerja Transportasi Nasional), (2009). Kebijakan dan strategi untuk meningkatkan efisiensi pengelolaan infrastruktur jalan secara berkelanjutan. Jakarta: Kantor Kementerian Koordinator Bidang Perekonomian Republik Indonesia.

Xu, Y., \& Tsai, Y. C. (2012). Financial Consequences of Delaying Pavement Rehabilitation: Case Study Using LTPP Data. Journal of Transportation Engineering, 138(8), 975-982.

Zhang, H., Keoleian, G. A., \& Lepech, M. D. (2012). Network-level Pavement Asset Management System Integrated with Life-cycle Analysis and Life-cycle Optimization. Journal of Infrastructure Systems, 19(1), 99-107. 